\title{
Effect of Different Types of Noises on Divergent Creativity in Young Adults
}

\author{
Dipam Sharma*, Aakash Gurbani, Kavya Manjunath, Dyuti Dutta, Hatice Guneli \\ Department of Psychology, CHRIST (Deemed to be University), Bengaluru, India \\ Email: *dipamsharma39122@gmail.com
}

How to cite this paper: Sharma, D., Gurbani, A., Manjunath, K., Dutta, D. and Guneli, H. (2021) Effect of Different Types of Noises on Divergent Creativity in Young Adults. Open Access Library Journal, 8: e7420.

https://doi.org/10.4236/oalib.1107420

Received: April 14, 2021

Accepted: June 15, 2021

Published: June 18, 2021

Copyright () 2021 by author(s) and Open Access Library Inc.

This work is licensed under the Creative Commons Attribution International License (CC BY 4.0).

http://creativecommons.org/licenses/by/4.0/

\begin{abstract}
Noise has always been considered a botheration. Previous literature has shown the adverse effects of noise on several aspects of cognition and task performance. However, a key idea in noise literature is that deeming certain sounds as unwanted is a complex task and requires considerable analysis and thought in order to enable us to reach an agreement about what is noise and what is not. This becomes more evident in the context of research conducted on the effects of noise on creativity, the results to which have been inconclusive. While there are studies which show the detrimental effects of noise on creativity, there is also some evidence suggesting that for highly original individuals, moderate level of noise may lead to an increase in creative performance. This study tried to find some clarity with respect to these findings. 120 undergraduate (66 male and 54 female) students between the age of 18 25 were divided into four groups. Each of the groups was given 5 tasks from $\mathrm{rCAB}$, while being exposed to silence, construction noise, sound of people talking, and traffic noise respectively. The group that took the test in silence performed the best, while the one exposed to traffic noise performed the worst. However, the results did not prove to be statistically significant. The study threw light on the high threshold of noise perception among the participants that could be attributed to any of the factors such as that of age or region. Future researches could look into individual differences that might affect performance under different noise simulations, thus providing more clarity to the findings.
\end{abstract}

\section{Subject Areas}

Psychology

\section{Keywords}

Noise, Creativity, Divergent Creativity, Types of Noises 
"I have long held the opinion that the amount of noise that anyone can bear undisturbed stands in inverse proportion to his mental capacity and therefore be regarded as a pretty fair measure of it."

-Arthur Schopenhauer

\section{Introduction}

Noise has always been considered as something distracting so much so that it is most commonly defined as any unwanted sound. What can be considered as noise is quite a subjective matter. However, humans have identified certain sounds that are more or less universally considered undesirable. In fact, decades of extensive research have introspected the impact of noise on cognition and task performance [1] [2].

Literature on noise studies has shown the adverse effects of brief and continuous noise on attention [3] [4], reading deficits and skill [5] and cognitive processing [6] [7]. Historically as well, noise has been considered as a botheration and research has demonstrated the negative side effects of this external, unwanted sound [8] [9] [10].

These scientific explorations have solidified the conspicuous belief that noise is distressing. However, a significant distinction needs to be made between noise and sound. Miller (1974) claims that "sound is of great value to man" [11]. It has always been resourceful to humans by warning them of danger and appropriately arousing and activating them. When this sound becomes excessive and undesirable it takes the form of noise. Another key idea raised by Miller is that deeming certain sounds as unwanted is a complex task and requires "considerable analysis and thought to enable us to reach agreement about what is noise and what is not" [11].

Creativity is the process of coming up with something new. Creative thinking refers to looking at the same thing with a different perspective. Thus, creative thinking is also generally referred to the phrase, "thinking out of the box". A closer look at different researches shows that external stimulus, like noise or music, tends to affect the creative performance of individuals, and convergent thinking in particular [12].

Mehta, Zhu and Cheema (2012) raised the question "Is Noise Always Bad?" The evidence with regards to the effects of noise on creativity is quite inconclusive [13]. In congruence with the previous findings, most studies have shown that noise constraints creativity [14] [15] [16]. At the same time there is also some evidence suggesting that for highly original individuals, moderate level of noise may lead to an increase in creative performance [17] [18]. Many of these researches have also proposed reasons as to why noise may affect creativity, ranging from arousal [19] to stress [14], oversensitivity and rate of habituation [19] and even attention span [15].

Toplyn (1991) in his study focused on whether it is the individual differences in creative potential that mediates the effect of noise on creative task perfor- 
mance [17]. It was seen that performance was enhanced for moderate levels of noise as compared to low or high. Also, the reason why noise as a stressor produced an increment in the overall performance on creative tasks is because the tasks required larger attention deployment. Therefore, from Toplyn's study we can explain that the more complex the task, the greater the degree of cue utilization needed for task solution.

Apart from individual differences, what might also affect performance on creative tasks is the rate of habituation and the sensitivity of an individual, Martindale (1989) provides anecdotal evidence suggesting extreme oversensitivity in eminent creative personalities. He also speculated that creative individuals take more time to get habituated to a stimulus.

Martindale and his colleagues (1996), also conducted an experiment on college students who took RAT [20] and a version of Alternate Uses Test [21], while being subjected to 20 bursts of $60 \mathrm{~dB}$ white noise. The results showed that people who scored high on the creativity tests were more physiologically responsive to the stimuli, i.e., noise. It also became clear that creative people take more time to habituate.

Joseph Kasof, in his study on creativity and breadth of attention hypothesised that creative performance is facilitated by wide breadth of attention [15]. Participants were first instructed to complete a measure of trait breadth of attention and then asked to write a poem alone in a quiet setting. Some of these participants were then randomly assigned to write another poem while being subjected to noise that was predictable, unpredictable and intelligible or unintelligible. The results showed that creative performance was impaired by exposure to noise, in particular, noise that was unpredictable and intelligible. The study concluded that breadth of attention was positively related to creative performance. Noise hindered creative performance more in people whose trait breadth of attention was relatively wide.

In a recent study conducted in 2019, Jessica Massonnie and her colleagues tried to find out whether moderate multi-talker noise promoted children's creativity, and measured the effects of the children's age, their working memory and selective attention on the same [22]. The process involved two idea generation tasks in which selective attention skills, verbal and visuospatial working memory were assessed along with behavioural tasks. The results of the study concluded that selective attention plays a significant role on the impact of classroom noise on children's ability to generate new ideas, in that young children with low selective attention skills produce fewer original ideas in the presence of noise than otherwise. There were no prominent age differences with regard to performance in selective attention activities but the same was noticed in the case of working memory. However, performance in the latter did not show any significant differences due to noise.

Mehta, Zhu and Cheema (2012) examined the effect of ambient noise on creativity through five experiments. A combination of multi-talker noise in a cafete- 
ria, roadside traffic and distant construction was blended to create a soundtrack of constantly varying background noise [13]. The noise was then manipulated to generate as low a sound level as 50 decibels, a moderate 70 decibels and as high as 85 decibels and played on speaker while the participants were made to complete the Remote Associates Test (RAT) and a shoe-polish problem solving task, to judge their creativity, on the basis of the two components of originality and appropriateness. It was observed that a moderate versus low level of ambient noise enhanced performance on creative tasks and increased the likelihood of one's buying innovative products. A high level of noise on the other hand hurt creativity. Process measures revealed that a moderate level of noise increased processing difficulty, inducing higher construal level and thus promoting abstract processing, which subsequently led to higher creativity. A high level of noise, however, reduced the extent of information processing, thus impairing creativity. The experiment, however, only tested convergent creativity using different levels of noise, and the research did not explore other types of creativity. Moreover, only one type of noise was measured and the effects of different noises weren't tested.

This research attempted to see if noise had any effect on creative performance. As discussed earlier, a lot of researchers have tried to look at the relationship between noise and various aspects of individual performance. Various studies have also looked at how noise and music differently affect creativity in people with differences in personality types and breadth of attention. Previous studies conducted on the effects of noise on creative performance, however, have mostly been inconclusive on whether the effect noise has on creative functioning is positive or negative. In the study conducted by Mednick and Mednick, a level of 80 $\mathrm{dB}$ of noise is seen to induce a marginal decrement in creativity as observed in a RAT test but this proof is contradicted with another study by Voss which shows that $79 \mathrm{~dB}$ level of noise causes an increment in creativity performance [18].

Previous work that attempted to measure the effects of noise levels on creativity focused more on convergent thinking, such as in the study by Mednick and Mednick, or in the study conducted by Mehta et al., wherein RAT tests were conducted to measure creativity [13]. Moreover, the few studies which have examined noise and its effects on divergent creativity have also taken other variables such as music into account. There has however been no significant study that has taken more than two different noise types into account and solely compared their differential effects on divergent creativity. This paper thus attempted to take several noise simulations, and examine the different effects they might have on an individual's performance on divergent creativity tasks.

As per the rationale elaborated above, the present study intended to answer the following questions:

- Does noise increase or decrease creativity?

- Do different types of noise have varied effects on performance in divergent creativity? 
It was also hypothesised that:

H0: Background noise has no effect on performance in divergent creativity tasks.

H0: There is no difference in how different noise types affect performance on creative tasks.

\section{Method}

\subsection{Operational Definitions}

There are certain terms that are important to note in the context of this study.

Noise. Noise refers to an external, unwanted sound that is deemed as unpleasant and disruptive.

Divergent Thinking. Divergent thinking refers to a "broad search for logical alternatives" that results in the production of multiple ideas to an open-ended problem (Guilford, 1975).

Ideational fluency. This refers to the ability to rapidly produce a series of ideas, words, or phrases related to a specific condition or object.

Ideational flexibility. This refers to the ability to create and use new mental categories and concepts to reorganize our experiences.

\subsection{Participants}

A total of 120 participants from CHRIST (Deemed to be University) were selected using convenience sampling. These were undergraduate students between the ages of 18 - 25. There were 66 male participants and 45 female participants. They were not equally divided between the groups.

The study excluded people who had been diagnosed with hearing difficulties, or any intellectual disabilities and severe psychological disorders.

\subsection{Research Design}

A quasi-experimental design was followed. The sample was divided into four groups, among which comparisons were then made on the basis of the effects of the different types of noise. There were four independent variables, that is, the four different types of noise environment simulations. The dependent variable was creativity, which was divided into the two components of ideational fluency and flexibility.

\subsection{Research Instruments}

The Runco Creativity Assessment Battery (Runco, 2011) was used for the experiment [23]. A total of five tests of divergent thinking were used from the battery: Alternate Titles Task, Many Uses Game, Many Instances Game, Better Products and Services Test, and Figural DT. The Alternate Titles Task required the participant to list alternative titles for the movies, plays and books listed in the task.

The Many Uses Game required the participant to think of as many alterna- 
tives as possible for everyday items listed in the game.

The Many Instances Game involved listing as many alternate ides as the participant could for a given thing. For example, if the given category was "round things", the participant could list tire, donuts coins and many other things.

The Better Products and Services measure requires the participants to think of ways in which the products given in the task could be improved. For example, how could a trash bin be improved.

In the Figural DT task, certain abstract figures were given and the participant had to list as many things as they could think that the figure might be.

These tests as a part of the Divergent Thinking tests as a whole provide an assessment of an individual's creative potential. The scores provide assessment of creativity in three major domains, i.e., ideational fluency, which represents the number of ideas an individual can generate, ideational flexibility, which represents the number of different conceptual categories used by an individual and lastly, ideational originality, which represents the statistical infrequency or uniqueness of ideas [24]. For this study, the two components of ideational fluency and ideational flexibility have been used (Table 1).

For validity, the various indices of DT, i.e., originality, fluency, and flexibility were correlated with two criterion variables, namely the Quick Estimate of Convergent Thinking (QECT) developed by Turkman and Runco (2013) [26] and Runco's Ideational Behavior Scale [27]. Several of the correlation were statistically significant $(<0.11)$. The highest coefficients were between Uses fluency $(\mathrm{r}=$ $0.28)$ and originality $(\mathrm{r}=0.23)$ with QECT. However, Runco et al. also point out several drawbacks with these findings. First, these tests lack discriminant validity, which shows whether the test of a concept is different from the tests designed to measure theoretically different concepts. Secondly, although the correlations were statistically significant, they were low.

Three soundtracks were used for the background noise stimulation, viz, construction noise, sound of people talking and traffic noise.

\subsection{Procedure}

The participants were randomly divided into 4 groups of 30 people each. The

Table 1. Reliability of fluency and originality.

\begin{tabular}{cc}
\hline Test & Fluency \\
\hline Titles & 0.72 \\
Uses & 0.49 \\
Instances & 0.84 \\
Better Products and Services & N/A \\
Realistic Presented Problems & 0.64 \\
Figures & 0.56 \\
\hline
\end{tabular}

Note: The reliability scores were obtained from the experiments conducted by Runco et al. (2016). These scores represent the inter-item reliability [25]. 
first group took the $5 \mathrm{rCAB}$ DT tests while the construction noise simulation played in the background. The second group was asked to take the test to the sound of people talking. The third group did the test while traffic noise simulation played in the background. The fourth group took the test with no added background sound. All the soundtracks were played in the same volume, at 80 $\mathrm{dB}$. The tests were conducted in a classroom setting with all doors and windows closed to prevent other sounds from interfering.

The tests were scored based on the guidelines provided by Mark Runco from the Manual for Administration and Scoring for the rCAB, 2015. Fluency is basically the number of distinct ideas given by the person, and it was calculated by simply counting the number of ideas. Flexibility refers to distinct categories that the person referred to while listing ideas. For example, buses, cars, bikes, trains et cetera would all come under the idea category of "vehicles", when asked to list things that move on wheels. The fluency and flexibility scores on all the tasks were then added for each individual to get one score each for both the categories.

\section{Results and Discussion}

The mean fluency score of subjects in Condition 1 (no noise) was the highest at $73(\mathrm{SD}=22.1)$ and their mean flexibility scores were also found to be highest at 60.43 (SD = 17.31). The mean fluency score of subjects exposed to traffic noise was found to be the lowest at $60(\mathrm{SD}=18.01)$ with an equally lower mean score at $53.93(\mathrm{SD}=15.69)$.

As seen in Table 2, the mean fluency score of subjects exposed to construction noise simulation was $69.73(\mathrm{SD}=24.96)$ with a mean flexibility of $58.5(\mathrm{SD}=$ 21.65). The mean fluency score of subjects exposed to the sound of people talking was 64.63( $(\mathrm{SD}=32.09)$ with mean flexibility score of $56.23(\mathrm{SD}=26.12)$.

As seen in Table 3, F value for frequency (1.453) was not significant ( $\mathrm{p}=$ $0.05)$. F value for fluency $(0.55)$ was also not significant $(\mathrm{p}=0.05)$. No significant differences in mean were noted between groups with regard to either frequency

Table 2. Mean and standard deviation scores.

\begin{tabular}{lcccc}
\hline \multirow{2}{*}{ Group } & \multicolumn{2}{c}{ Mean } & \multicolumn{2}{c}{ Standard Deviation } \\
\cline { 2 - 5 } & Fluency & Flexibility & Fluency & Flexibility \\
\hline 1 (No Noise) & 73 & 60.43 & 22.108 & 17.310 \\
2 (Construction) & 69.73 & 58.50 & 24.966 & 21.655 \\
3 (People Talking) & 64.63 & 56.23 & 32.091 & 26.121 \\
4 (Traffic) & 60.63 & 53.93 & 18.012 & 15.691 \\
\hline
\end{tabular}

Table 3. F score and sum of squares for fluency and flexibility.

\begin{tabular}{cccc}
\hline Variable & $\mathrm{N}$ & Sum of Squares (Between Groups) & $\mathrm{F}$ \\
\hline Fluency & & 2688.200 & 1.453 \\
Flexibility & 150 & 711.825 & 0.559 \\
\hline
\end{tabular}


or flexibility in the divergent creativity task.

As discussed previously, the average performance of the group that was exposed to no noise simulation was better than that of other groups. Existing literature has shown that high levels of ambient noise negatively affect creativity. The purpose of this study was to see whether different types of noise played at a constant decibel level of around $80 \mathrm{~dB}$, has any significant differences in the level of performance in divergent creativity tasks. It was seen that the mean over-all performance of the group exposed to a simulation of traffic noise was comparatively the worst, followed by the group exposed to the sound of people talking, followed by the group exposed to the construction noise simulation, and finally the group that wasn't exposed to any additional noise stimuli performed the best. This finding is supported by previous researches which have shown that talking noises can be distracting for individuals [28].

A possible reason for comparatively good performance despite noise could be the subjective perception and creativity levels of the subjects. As speculated in previous researches, acceptance of noise may be an intrinsic property of an individual. The loci of control and self-control seem to influence acceptable noise levels [29]. Previous research also suggests that increased subjective annoyance with respect to noise is related to decrease in mental health. Thus, subjective perception of noise could likely have also affected creative task performance.

The sample chosen for this study mostly comprised of students living in an area prone to high noise levels. This could have affected the perception of noise among some of the subjects as a significant environmental factor that was additionally imposed. This might be considered as a limitation of the study.

\section{Conclusions}

The hypotheses have been accepted since no significant effects of noise on performance in divergent creativity tasks were found in any of the groups, as compared to the no-noise environment. There were also no significant differences in the effect of the different types of noise on performance in divergent creativity tasks for the various groups.

The major limitation of this study was its inability to successfully counter individual differences by filtering people according to their inherent creativity. These might have affected the results as some people are naturally more creative than others, in which case the comparison would not have been fair. A second limitation was the lack of a soundproof room, which despite precautions, may have allowed certain noises apart from the ones artificially administered, to interfere with the results.

Future researches on this could take up a larger sample size that would help to prove if the slight differences in performance noted in this study, can be significant. Moreover, since the sample of this study consisted of a specific demographic, it wasn't helpful in determining age and regional differences. Gathering data from different areas of a state, for example, city and village, would perhaps 
help in determining individual differences as a result of daily exposure to noise. The same study, if conducted in a small town or village might yield different results.

\section{Conflicts of Interest}

The authors declare no conflicts of interest regarding the publication of this paper.

\section{References}

[1] Dalton, B.H. and Behm, D.G. (2007) Effects of Noise and Music on Human and Task Performance: A Systematic Review. Occupational Ergonomics, 7, 143-152.

[2] Belojevic, G., Jakovljevic, B. and Slepcevic, V. (2003) Noise and Mental Performance: Personality Attributes and Noise Sensitivity. Noise \& Health, 6, 77-89. https://www.noiseandhealth.org/text.asp?2003/6/21/77/31680

[3] Hockey, G.R.J. (1970) Effect of Loud Noise on Attentional Selectivity. Quarterly Journal of Experimental Psychology, 22, 28-36. https://doi.org/10.1080\%2F14640747008401898

[4] Kujala, T., Shtyrov, Y., Winkler, I., Saher, M., Tervaniemi, M., Sallinen, M., et al. (2004) Long-Term Exposure to Noise Impairs Cortical Sound Processing and Attention Control. Psychophysiology, 41, 875-881. https://doi.org/10.1111/j.1469-8986.2004.00244.x

[5] Evans, G.W. and Maxwell, L. (1997) Chronic Noise Exposure and Reading Deficits: The Mediating Effects of Language Acquisition. Environment and Behavior, 29, 638-656. https://doi.org/10.1177\%2F0013916597295003

[6] Enmarker, I. and Boman, E. (2004) Noise Annoyance Responses of Middle School Pupils and Teachers. Journal of Environmental Psychology, 24, 527-536. https://doi.org/10.1016/j.jenvp.2004.09.005

[7] Lercher, P., Evans, G.W. and Meis, M. (2003) Ambient Noise and Cognitive Processes among Primary Schoolchildren. Environment and Behavior, 35, 725-735. https://doi.org/10.1177\%2F0013916503256260

[8] Kryter, K. (1994) The Handbook of Hearing and the Effects of Noise: Physiology, Psychology, and Public Health. Brill, Leiden.

[9] Passchier-Vermeer, W. and Passchier, W.F. (2000) Noise Exposure and Public Health. Environmental Health Perspectives, 108, 123-131.

https://doi.org/10.1289/ehp.00108s1123

[10] Rabinowitz, P.M., Galusha, D., Kirsche, S.R., Cullen, M.R., Slade, M.D. and Dixon-Ernst, C. (2011) Effect of Daily Noise Exposure Monitoring on Annual Rates of Hearing Loss in Industrial Workers. Occupational and Environmental Medicine, 68, 414-418. https://doi.org/10.1136/oem.2010.055905

[11] Miller, J.D. (1974) Effects of Noise on People. The Journal of the Acoustical Society of America, 56, 729-764. https://doi.org/10.1121/1.1903322

[12] Doyle, A. (2019) Why Employers Value Creative Thinking. https://www.thebalancecareers.com/creative-thinking-definition-with-examples-20 $\underline{63744}$

[13] Mehta, R., Zhu, R. and Cheema, A. (2012) Is Noise Always Bad? Exploring the Effects of Ambient Noise on Creative Cognition. Journal of Consumer Research, 39, 784-799. https://doi.org/10.1086/665048 
[14] Hillier, A., Alexander, J.K. and Beversdorf, D.Q. (2006) The Effect of Auditory Stressors on Cognitive Flexibility. Neurocase, 12, 228-231. https://doi.org/10.1080/13554790600878887

[15] Kasof, J. (1997) Creativity and Breadth of Attention. Creativity Research Journal, 10, 303-315. https://doi.org/10.1207/s15326934crj1004_2

[16] Martindale, C. and Greenough, J. (1973) The Differential Effect of Increased Arousal on Creative and Intellectual Performance. The Journal of Genetic Psychology, 123, 329-335. https://doi.org/10.1080/00221325.1973.10532692

[17] Toplyn, G. and Maguire, W. (1991) The Differential Effect of Noise on Creative Task Performance. Creativity Research Journal, 4, 337-347. https://doi.org/10.1080/10400419109534410

[18] Voss, H.G. (1977) The Effect of Experimentally Induced Activation on Creativity. The Journal of Psychology, 96, 3-9. https://doi.org/10.1080/00223980.1977.9921411

[19] Martindale, C., Anderson, K., Moore, K. and West, A.N. (1996) Creativity, Oversensitivity, and Rate of Habituation. Personality and Individual Differences, 20, 423-427. https://doi.org/10.1016/0191-8869(95)00193-X

[20] Mednick, M.T. (1967) Relationship of the Ammons Quick Test of Intelligence to Other Ability Measures. Psychological Reports, 20, 523-526. https://doi.org/10.2466\%2Fpr0.1967.20.2.523

[21] Christensen, P.R., Guilford, J.P., Merrifield, P.R. and Wilson, R.C. (1960) Alternate Uses. Sheridan Psychological Services, Beverly Hills.

[22] Massonnié, J., Rogers, C.J., Mareschal, D. and Kirkham, N.Z. (2019) Is Classroom Noise Always Bad for Children? The Contribution of Age and Selective Attention to Creative Performance in Noise. Frontiers in Psychology, 10, Article No. 381. https://doi.org/10.3389/fpsyg.2019.00381

[23] Runco, M.A. (2011) Runco Creativity Assessment Battery (rCAB). Creativity Testing Services.

[24] Beketayev, K. and Runco, M.A. (2016) Scoring Divergent Thinking Tests by Computer with a Semantics-Based Algorithm. Europe's Journal of Psychology, 12, 210-220. https://doi.org/10.5964/ejop.v12i2.1127

[25] Runco, M.A., Williams, R. and Berlow, E. (2016) Mapping the Themes, Impact, and Cohesion of Creativity Research over the Last 25 Years. Creativity Research Journal, 28, 385-394. https://doi.org/10.1080/10400419.2016.1230358

[26] Turkman, B. and Runco, M.A. (2013) Quick Estimate of Convergent Thinking [Measurement Instrument].

[27] Runco, M.A., Plucker, J.A. and Lim, W. (2001) Development and Psychometric Integrity of a Measure of Ideational Behavior. Creativity Research Journal, 13, 393-400. https://doi.org/10.1207/S15326934CRJ1334_16

[28] Chamorro-Premuzic, T., Swami, V., Terrado, A. and Furnham, A. (2009) The Effects of Background Auditory Interference and Extraversion on Creative and Cognitive Task Performance. International Journal of Psychological Studies, 1, 1-9. https://doi.org/10.5539/ijps.v1n2p2

[29] Xia, S., Ma, X., Wang, Y., Houle, M. E., Zhou, S., Erfani, S. and Bailey, J. (2018) Dimensionality-Driven Learning with Noisy Labels. 35 th International Conference on Machine Learning, Sweden, 10-15 July 2018, 3355-3364. 